\title{
Editorial
}

\section{Functional Nanomaterials for Energy Applications}

\author{
Rupesh S. Devan, ${ }^{1}$ Yuan-Ron Ma, ${ }^{2}$ Jin-Hyeok Kim, ${ }^{3}$ \\ Raghu N. Bhattacharya, ${ }^{4}$ and Kartik C. Ghosh ${ }^{5}$ \\ ${ }^{1}$ Department of Physics, University of Pune, Pune 411007, India \\ ${ }^{2}$ Department of Physics, National Dong Hwa University, Hualien 97401, Taiwan \\ ${ }^{3}$ Department of Materials Science and Engineering, Chonnam National University, Gwangju 500-757, Republic of Korea \\ ${ }^{4}$ National Renewable Energy Laboratory, Golden, CO 80401, USA \\ ${ }^{5}$ Department of Physics, Astronomy and Materials Science Missouri State University, Springfield, MO 65897, USA
}

Correspondence should be addressed to Rupesh S. Devan; devan_rs@yahoo.co.in and Yuan-Ron Ma; ronma@mail.ndhu.edu.tw

Received 16 February 2015; Accepted 16 February 2015

Copyright (C) 2015 Rupesh S. Devan et al. This is an open access article distributed under the Creative Commons Attribution License, which permits unrestricted use, distribution, and reproduction in any medium, provided the original work is properly cited.

To leap forward from the energy crisis issues and improve lifestyle, we all are looking positively toward nanomaterials or nanostructures. Therefore, the exploration of new features of both typical and novel materials at the nanoscale level is playing important role in the development of innovative and improved energy technologies that have the capability of conserve/convert energy at large extend. By tailoring the surface morphology of materials in its nanoforms, the functional properties can be significantly adapted and specifically combined to produce highly potent multifunctional materials for conversion, storage, and consumption of energy in various forms. The papers selected for this special issue represent a good panel for addressing various energy applications including solar cell, fuel cells, nanofluid twisters, and gas sensors. Of course, the selected topic and the papers are not an exhaustive representation of the utilization of functional nanomaterials for energy applications. Nonetheless, they represent the rich and many-facet knowledge, which we have the pleasure of sharing with the readers.

The special issue contains five papers, where brief review on the fabrication of electrospun polymer electrolyte membrane for direct methanol fuel cell is presented. One of the papers brings up the method to utilize carbon nanotube (CNT) and graphene modified carbon-cloth electrode for fabrication of membrane free air-cathode microbial fuel cells (MFC). Another paper accounted the QDSCs performance of $\mathrm{CdS}$ with various doping concentration of $\mathrm{Cu}$. Two other papers reported the sulfur dioxide sensing ability of tungsten oxide after niobium loading and one paper mentioned thermal performance of conic cut twist tape inserts with $\mathrm{SiO}_{2}$ and $\mathrm{TiO}_{2}$ nanofluids.

A review article, titled "A Review on the Fabrication of Electrospun Polymer Electrolyte Membrane for Direct Methanol Fuel Cell," authored by H. Junoh et al., reported the development of electrospun polymer electrolyte membrane for direct methanol fuel cell (DMFC). They reported the details and benefits of electrospun technology. This electrospun technique is capable of sustaining proton conductivity and also suppresses methanol permeability without jeopardizing the fuel cell system. This review paper described in detail the electrospun-sulfonated poly(ether ether ketone) (SPEEK) for fuel cell application, as well as optimizing the degree of sulfonation for spinnable SPEEK solution.

The paper, titled "Characterization of Carbon Nanotube/Graphene on Carbon Cloth as an Electrode for AirCathode Microbial Fuel Cells," authored by H.-Y. Tsai et al., investigated the performance of a single-chamber microbial fuel cell (MFC) that uses carbon nanotube (CNT) and graphene-modified carbon-cloth electrodes. They developed a process for fabricating carbon-based modified electrodes and Escherichia coli HB101 in an air-cathode MFC. They, finally, found that the power density of MFCs is to be improved by applying a coat of either graphene or CNT to a carbon-cloth electrode, and the graphene-modified electrode exhibits superior performance.

The paper, titled "Effects of Different Doping Ratio of $\mathrm{Cu}$ Doped CdS on QDSCs Performance," authored by X. Zhu et al., investigated the effects of $\mathrm{Cu}$ doping concentration on 
the performance of CdS quantum dot sensitized solar cell prepared by successive ionic layer adsorption and reaction (SILAR) method. Their experimental results showed $\mathrm{Cu}$ doped CdS quantum dot sensitized solar cells (QDSCs) have higher open circuit voltage, short circuit current density, and photoelectric conversion efficiency than undoped CdS QDSCs. They also found that, in a certain range, the lower the doping ratio of $\mathrm{Cu}$, the better the performance of QDSCs.

The paper, titled "Effects of Niobium-Loading on Sulfur Dioxide Gas-Sensing Characteristics of Hydrothermally Prepared Tungsten Oxide Thick Film," authored by V. Kruefu et al., reported the hydrothermal synthesis of $\mathrm{WO}_{3}$ roads which were further loaded with $\mathrm{Nb}$ nanoparticles with various weight percent. The loading of $\mathrm{Nb}$ nanoparticles along the surface of $\mathrm{WO}_{3}$ rods improved sulfur dioxide sensing performance. They reported $\mathrm{Nb}$ nanoparticle loading is an effective mean to improve the sensing ability of $\mathrm{WO}_{3}$ nanostructures.

The paper, titled "Comparative Studies on Thermal Performance of Conic Cut Twist Tape Inserts with $\mathrm{SiO}_{2}$ and $\mathrm{TiO}_{2}$ Nanofluids," written by S. D. Salman et al., compared performance of various conic cut twist tapes inserted in $\mathrm{SiO}_{2}$ and $\mathrm{TiO}_{2}$ nanofluids and found enhancement in heat transfer rate by increasing concentration of nanoparticles in nanofluid. Finally they implemented empirical correlations for their experimental inventions.

\section{Acknowledgments}

We would like to thank the authors for their excellent contributions and patience in assisting us. Finally, the fundamental work of all the reviewers of these papers is also very warmly acknowledged.

Rupesh S. Devan Yuan-Ron Ma Jin-Hyeok Kim

Raghu N. Bhattacharya Kartik C. Ghosh 

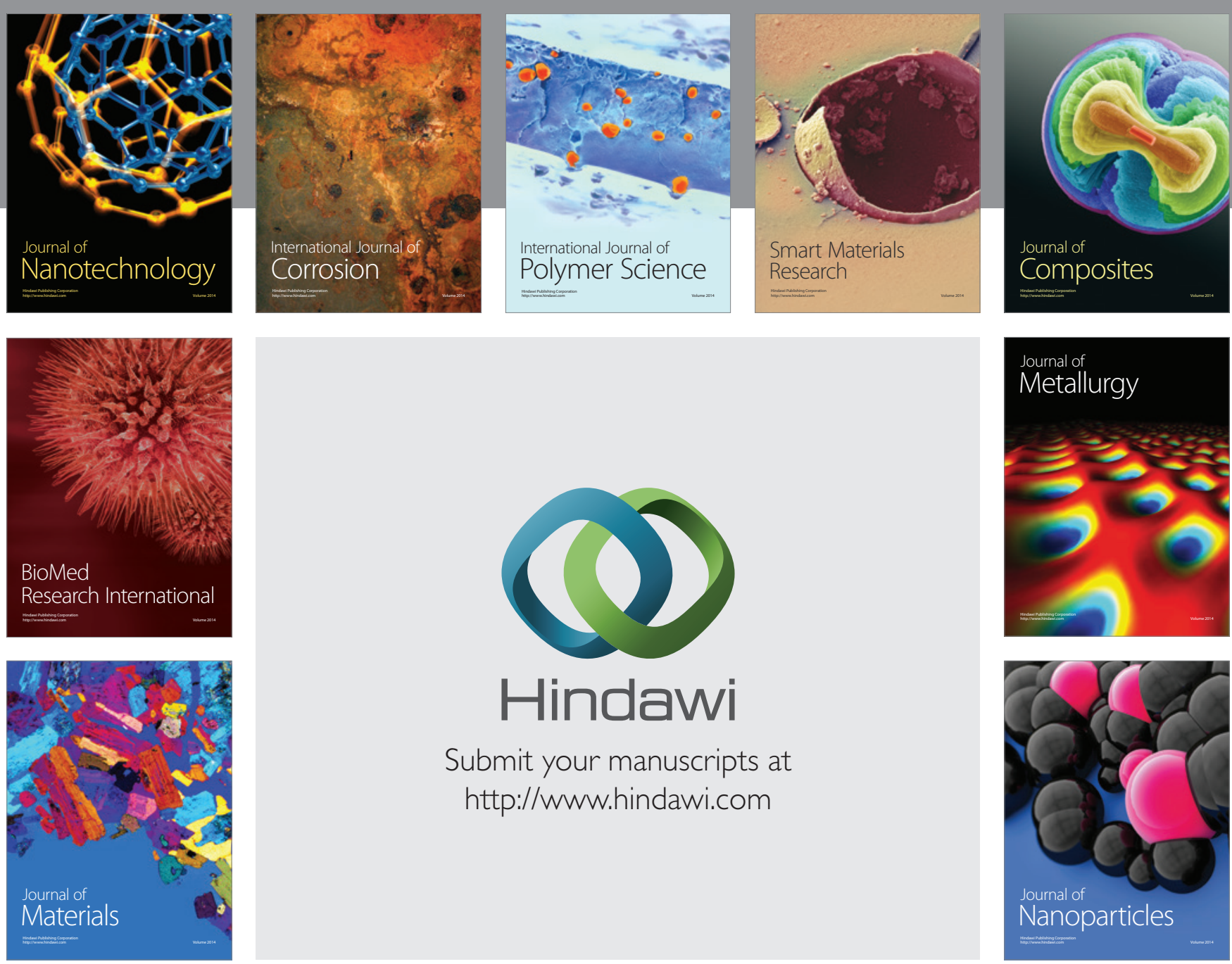

Submit your manuscripts at http://www.hindawi.com
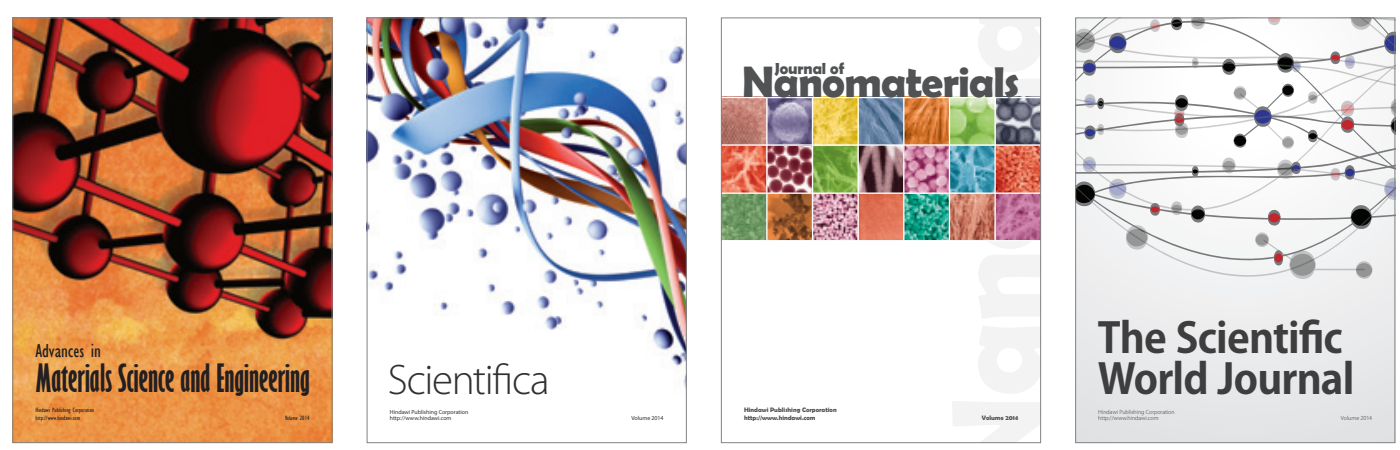

\section{The Scientific World Journal}
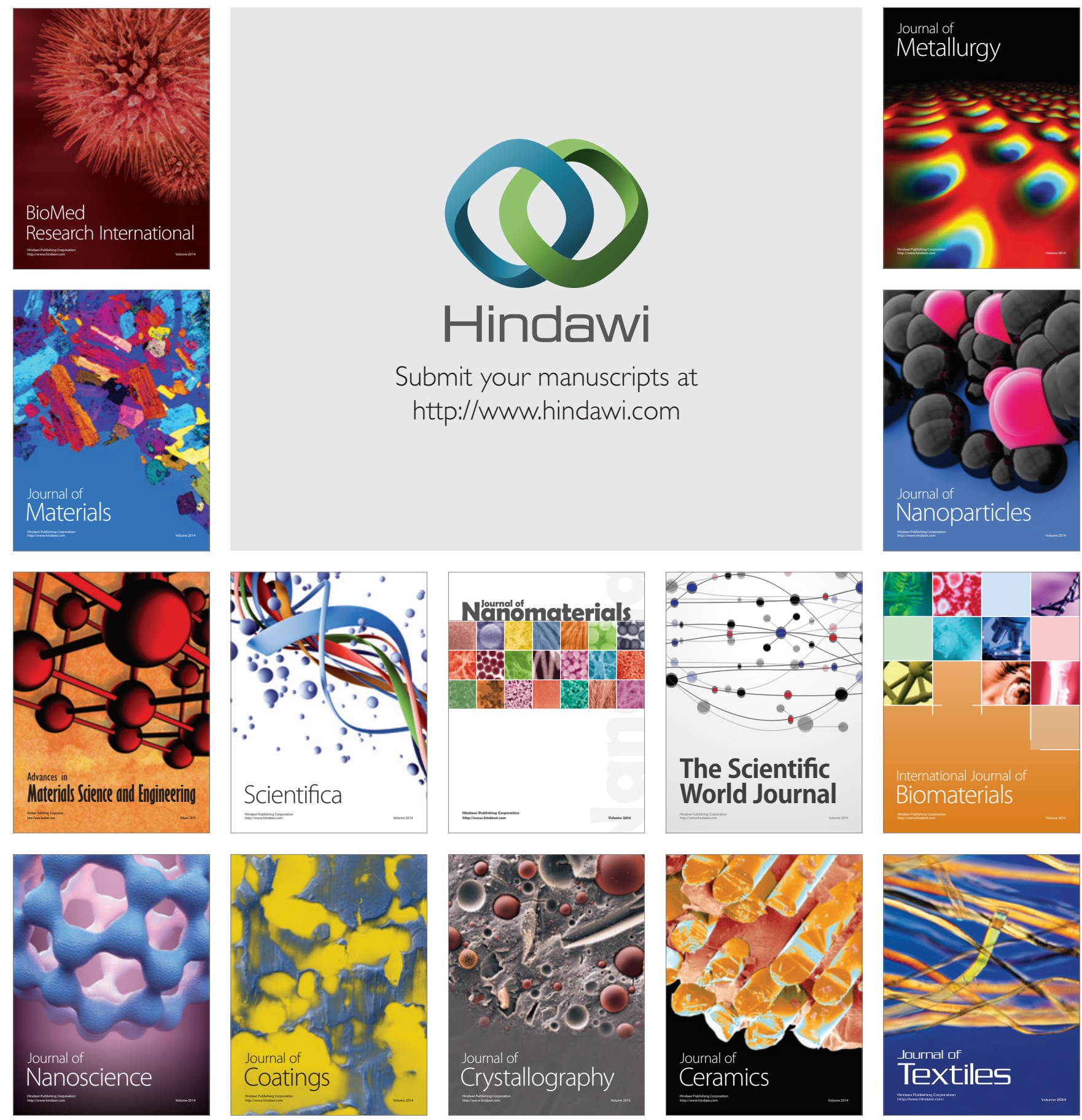